\title{
ESTUDO DE CASO: A DEMANDA POR SOFT SKILLS E HARD SKILLS NO ENGENHEIRO DE PETRÓLEO PELO MERCADO DE TRABALHO DA INDÚSTRIA 4.0
}

\author{
Maria Eduarda Villela Marinho - mariamarinho@id.uff.br \\ Thalys Gean Maciel Martins - tgean@id.uff.br
}

Universidade Federal Fluminense, Escola de Engenharia, TEQ - Departamento de Engenharia Química e de Petróleo, Rua Passos da Pátria, 156 - Bloco D - Sala 264, 21.210-240 - Niterói RJ.

Resumo: No panorama da Indústria 4.0, a transformação digital entra em cena remodelando de vez a indústria e o novo perfil de profissional demandado pelas empresas. $O$ artigo adota como principal análise o Engenheiro de Petróleo e Gás, estudando a relevância das soft skills e hard skills no mercado de trabalho atual. Assim, são discutidos: os agentes responsáveis por promover tais habilidades, as oportunidades oferecidas pela Universidade Federal Fluminense que permitem essa promoção e os resultados de um estudo de caso sobre a qualificação de alunos e profissionais da Engenharia de Petróleo com relação a soft skills e hard skills.

Palavras-chave: Engenharia de Petróleo. Óleo e Gás. Soft skills. Hard skills. Mercado de Trabalho.

\section{INTRODUÇÃO}

$\mathrm{Na}$ atual era pós $4^{\mathrm{a}}$ Revolução Industrial, corporações de diversos ramos se transformam constantemente no mundo todo adotando novas tecnologias em ritmo acelerado, enxergando nessa mudança de era a oportunidade de se destacar e liderar o mercado. Enquanto que algumas indústrias apenas iniciaram o investimento na analítica frente às demandas atuais de transformação digital, sendo o Big Data ainda uma novidade, lidar com um grande volume de dados não é novidade para o setor de Óleo e Gás pois este sempre dependeu de ter uma tecnologia muito avançada para conseguir operar.

Muitas das organizações de óleo e gás seguem uma estratégia de transformação digital menos disruptiva, apenas acompanhamento as tendências e incorporando tecnologias já testadas a fim de gerar resultados rápidos a custos razoáveis. No entanto, estas estão ainda preparando suas bases para reestruturações mais amplas em breve, pois para tornar-se um dos líderes entre concorrentes é essencial dedicar-se à inovação tecnológica, isto é, uma total digitalização da organização, de seus processos, operações, modelo de negócios e cultura. Esse panorama demanda uma mão-de-obra qualificada para trabalhar com a Indústria 4.0. Com base nisso, a dedicação ao desenvolvimento de soft e hard skills é um atalho para o sucesso no mercado, uma vez que o setor caminha para um cenário promissor ainda altamente competitivo, tornando-se um tema relevante para se analisar e, logo, a motivação do presente artigo. 
As soft skills dizem respeito às competências geradas pela personalidade do indivíduo, isto é, consistem em competências mentais, comportamentais e sociais. Essas qualidades são aquelas que podem influenciar na execução de uma tarefa com relação a aspectos como: ritmo, eficiência, segurança, união. Por exemplo, algumas soft skills são a flexibilidade, proatividade, organização, comunicação, responsabilidade, liderança e ética. Por sua vez, as hard skills dizem respeito às espécies de conhecimentos específicos e técnicas que expandirão os limites de uma pessoa de acesso à informação e à recursos, permitindo realizar algum trabalho com mais riqueza e qualidade. São competências aprendidas e facilmente quantificadas ou avaliadas. Exemplos de hard skills são os domínios de excel, de contabilidade, de idiomas, de programação, de gestão de projetos, entre cursos e outros.

\section{PERSPECTIVAS DO SETOR SOBRE O ENGENHEIRO DE PETRÓLEO}

A oferta de petróleo do Pré-Sal cresce cada vez mais desde seu descobrimento, passando a representar 62.3\% da produção nacional total de 2019. Segundo a ANP (Agência Nacional do Petróleo, Gás e Biocombustíveis), a produção nacional de petróleo cresceu 7.8\% em 2019, liderada pelo aumento da produção do Pré-Sal de 521.5 milhões de barris em 2018 para 634 milhões de barris. A produção de gás natural subiu também $9.5 \%$, marcando o décimo ano consecutivo de aumento. Sendo assim, o Brasil se manteve na posição de $10^{\circ}$ maior produtor de petróleo no mundo e ocupa o posto de maior produtor da América Latina (ANP, 2020).

Para saber aproveitar a vantagem desse potencial, faz-se ainda mais essencial o papel da automação, que estimula a geração de insights sobre como utilizar enormes quantidades de dados disponíveis que não têm todo o seu potencial explorado. A partir disso, é possível utilizálos de formas melhores e mais variadas, como facilitando tomada de decisões referentes a dados e eventos anômalos, gerando a manutenção preditiva, garantindo segurança operacional, reduzindo o tempo de inatividade e aumentando a produção. Destaca-se a importância das tecnologias digitais para a criação de novas vantagens sustentáveis a longo prazo, pois organizações lideram cada vez mais projetos de energia limpa e baixo risco de acidentes ambientais.

Dessa forma, empresas da indústria de Óleo e Gás nacional têm dado grande enfoque à inovação e à tecnologia, como Deep Learning, Internet das Coisas (IoT), Big Data e Inteligência Artificial, necessitando de profissionais qualificados para fazer esse progresso acontecer. Por sua vez, os profissionais que são vistos como qualificados devem ter experiências que explorem competências de dois âmbitos. Um deles é o comportamental, sendo a parte que revela potencial para criar soluções inovadoras, capacidade esta que é bem conceituada no mundo por meio do famoso termo em inglês thinking outside the box. O outro é o intelectual, sendo a parte que revela potencial para desenvolver ou controlar novas ferramentas, como conhecimento em análise de dados, robótica, softwares, idiomas, programação e inteligência artificial. Este último âmbito se mostra importante sabendo que a automatização constrói um futuro voltado cada vez mais a funções de monitoramento de um trabalho que é realizado integralmente pelas máquinas. 


\section{A UNIVERSIDADE FEDERAL FLUMINENSE NA FORMAÇÃO DO ENGENHEIRO DE PETRÓLEO}

Quanto à qualidade da formação superior do Engenheiro de Petróleo, identifica-se, primeiramente, uma responsabilidade por parte da universidade e do professor. $\mathrm{O}$ aluno, por sua vez, deve investir continuamente em oportunidades que encontrar dentro ou fora da universidade durante a graduação e aprender a investir em si mesmo de forma mais inteligente.

\subsection{O Professor e a Grade Curricular}

A Proposta Curricular para os Cursos de Engenharia de Petróleo, elaborada por uma comissão da Society of Petroleum Engineers (SPE) - Seção Brasil (SHECAIRA, 2017), enfatiza a importância de se trabalhar competências comportamentais. Entretanto, não podem ser adquiridas simplesmente por meio da compreensão de seus conceitos pois, para se consolidarem, precisam ser continuamente praticadas e demonstradas. Nesse sentido, é essencial que haja esforços por parte dos professores em não apenas aplicar metodologias que busquem o desenvolvimento de domínio teórico, mas planejar e pôr em prática, com sucesso, estratégias de aprendizado prático que demandem senso crítico, utilização de softwares de auxílio ao conteúdo sendo aprendido, interpretação de dados obtidos empiricamente etc.

Outra limitação detectada em muitas grades curriculares é a ausência de disciplinas que desenvolvam competências como gerenciamento de pessoas, gestão de riscos, negociação, planejamento de projetos, ou demais técnicas vantajosas para se atuar na condução de equipes de projetos ou de processos produtivos e administrativos nas organizações. Os trabalhos em equipe, por sua vez, promovem a união de integrantes com diferentes personalidades e habilidades em um mesmo grupo, o que é pertinente pois o Engenheiro de Petróleo é um profissional dinâmico que está inserido em equipes multidisciplinares devido às operações complexas do setor.

Observando essas áreas, nota-se que os currículos se encontram bem distribuídos nas áreas de conhecimentos técnicos em Engenharia, com exceção do campo de Modelagem e Matemática Computacional, cuja valorização crescente é, justamente, o que o artigo presente busca enfatizar. Tal condição decorre da deficiência de uma infraestrutura computacional adequada, a qual exige máquinas com alta capacidade de processamento de dados e convênios com empresas de softwares de modelagem para obtenção de licenças institucionais (SILVA e GUIMARÃES, 2018). Nesse cenário, é preciso que as ementas do curso se atualizem a fim de atender às novas demandas de mercado, enquanto que os professores se preocupem com relação a metodologia de ensino que executam.

\subsection{Atividades Extracurriculares}

Durante os anos de graduação, o estudante tem a possibilidade de participar de diversos grupos e programas acadêmicos que desenvolvam hard e soft skills. Apesar de conceitualmente diferentes, todas essas atividades contribuem eficientemente para a construção do Engenheiro de Petróleo, minimizando as carências estruturais ou pessoais existentes. No Quadro 1, disposto a seguir, são citadas e descritas as atividades extracurriculares existentes na Universidade Federal Fluminense (UFF) cujos esforços são direcionados ao curso de Engenharia de Petróleo. 
Quadro 1 - Atividades Extracurriculares da UFF

\begin{tabular}{|c|c|c|}
\hline Nome & Descrição & Objetivo \\
\hline PetroPET & $\begin{array}{l}\text { Programa de Educação } \\
\text { Tutorial em } \\
\text { Engenharia de Petróleo }\end{array}$ & $\begin{array}{l}\text { É um grupo voltado para atividades de pesquisa e extensão. O grupo } \\
\text { realiza publicações em congressos, organiza a semana acadêmica e cria } \\
\text { projetos voltados para o engrandecimento do curso. }\end{array}$ \\
\hline DAEP & $\begin{array}{l}\text { Diretório Acadêmico } \\
\text { de Engenharia de } \\
\text { Petróleo }\end{array}$ & $\begin{array}{l}\text { Busca formas de proporcionar uma experiência agradável ao aluno } \\
\text { enquanto na universidade, possui projetos que visam melhorar o } \\
\text { desempenho acadêmico dos alunos por meio de monitorias voluntárias } \\
\text { e projetos que buscam integrar o aluno com o curso. }\end{array}$ \\
\hline $\begin{array}{c}\text { P\&Q } \\
\text { Engenharia Jr. }\end{array}$ & $\begin{array}{c}\text { Empresa Júnior da } \\
\text { UFF }\end{array}$ & $\begin{array}{c}\text { A empresa é composta apenas por alunos e realiza projetos para empresas } \\
\text { com a orientação de um professor, tendo o objetivo de proporcionar } \\
\text { experiência profissional e empreendedora aos membros, antes que estes } \\
\text { iniciem no mercado de trabalho. }\end{array}$ \\
\hline PetroUFF & $\begin{array}{l}\text { Semana Fluminense de } \\
\text { Petróleo }\end{array}$ & $\begin{array}{l}\text { O evento tem como propósito qualificar os alunos, buscando oferecer } \\
\text { conhecimento extra ao que o curso de graduação disponibiliza, ajudando, } \\
\text { desse modo, a complementar a formação profissional dos mesmos. }\end{array}$ \\
\hline $\begin{array}{l}\text { Capítulo } \\
\text { Estudantil SPE } \\
\text { UFF }\end{array}$ & $\begin{array}{c}\text { Society of Petroleum } \\
\text { Engineers }\end{array}$ & $\begin{array}{l}\text { Nesta sociedade internacional composta por profissionais da indústria do } \\
\text { petróleo, cada capítulo estudantil visa aproximar os estudantes dos } \\
\text { profissionais da indústria, realizando eventos e palestras. }\end{array}$ \\
\hline PetroBowl & Grupo de Competição & $\begin{array}{l}\text { Os alunos são preparados para competir no evento PetroBowl, uma } \\
\text { competição internacional de perguntas sobre a indústria do petróleo que } \\
\text { envolve equipes de universidades de todo o mundo. }\end{array}$ \\
\hline
\end{tabular}

Fonte: Elaboração Própria

Além dessas atividades específicas para alunos do curso, o aluno da UFF pode participar de atividades mais gerais. Por meio de um projeto de Iniciação Científica (IC), o aluno pode aprender a lidar com responsabilidades, prazos e organização, a desenvolver senso crítico e comunicação, além de poder aprender softwares específicos. Já realizando atividade de monitoria, o aluno desenvolve oratória, liderança, empatia e aprende a ouvir. Outra oportunidade é o Minor em Empreendedorismo e Inovação, o qual é uma formação complementar em nível de graduação que habilita o estudante a desenvolver atitude empreendedora, realizar o plano de negócios, a gestão de processos, de pessoas, de finanças e marketing.

Ainda, é possível a participação em várias equipes de competição, alguns programas de extensão, algumas Empresas Juniores fundadas por outros cursos, cursos de línguas estrangeiras de forma gratuito (PULE) ou de baixo valor (PROLEM). Analisando essas iniciativas, pode-se 
inferir que o curso de Engenharia de Petróleo da UFF detém muitos programas que podem auxiliar na construção do Engenheiro do futuro.

Outro ponto importante é o contato dos alunos com o mercado de Óleo e Gás, sendo bastante interessante que a participação em palestras, workshops, minicursos, visitas técnicas etc. Essas atividades permitem relatar problemas reais em que as habilidades comportamentais, juntamente com as habilidades técnicas, foram fundamentais para o sucesso na trajetória ou serviço de alguém e apresentar uma visão sistêmica do setor, sua economia, desafios e novas tecnologias.

\section{ESTUDO DE CASO}

Uma pesquisa em formato de formulário foi desenvolvida a fim de compreender melhor sobre a influência atual das universidades na formação em Engenharia de petróleo, sendo o principal objetivo acessar experiências e opiniões daqueles que já foram estudantes curso. Os parâmetros centrais de análise por esse público que permitirão identificar pontos fortes e fracos da universidade nesse processo de formação de qualidade são as soft skills e as hard skills. Assim, as questões foram elaboradas de modo que as avaliações acerca das soft skills e acerca das hard skills fossem demarcadas e comparadas.

O formulário, em sua parte introdutória, descrevia seu objetivo e esclarecia os conceitos de soft skills e hard skills. Seu método de divulgação ocorreu de forma online por meio das plataformas LinkedIn e WhatsApp, sendo seu preenchimento restrito apenas àqueles indivíduos que estão ou já estiveram regularmente inscritos em um curso de graduação de Engenharia de Petróleo de alguma universidade brasileira. Ou seja, a pesquisa abrange avaliações tanto de estudantes quanto de profissionais já formados, sendo não necessário realizar tal distinção uma vez que o intuito é acessar suas experiências acadêmicas. Por fim, ressalta-se que os alunos que responderam pertencem a períodos diversos do curso e a universidades que não sejam especificamente a Universidade Federal Fluminense.

O total de formulários respondidos foi de 174. A seguir serão apresentadas e discutidas as perguntas do formulário e seus resultados. Informa-se que todas as perguntas eram objetivas, isto é, perguntas cuja única resposta deveria ser selecionada dentre as opções presentes, como uma escala de 1 a 10 nas primeiras quatro questões e níveis de sentimento em demais questões.

I. De 0-10, para conseguir ser um Engenheiro de Petróleo bem sucedido, quão determinantes você considera que são as:

$$
\begin{gathered}
\text { hard skills }-81,0 \% \text { classificaram como } 8 \text { a } 10 \\
17,2 \% \text { classificaram como } 5 \text { a } 7 \\
1,8 \% \text { outros } \\
\text { soft skills }-77,7 \% \text { classificaram como } 8 \text { a } 10 \\
21,2 \% \text { classificaram como } 5 \text { a } 7 \\
1,1 \% \text { outros }
\end{gathered}
$$

Percebe-se, portanto, que a grande maioria dos respondentes considera hard skills e soft skills extremamente determinantes para ser bem sucedido. De toda forma, é possível notar que aqueles consideram hard skills um pouco mais determinantes que soft skills, visto que parte dos respondentes rebaixou sua avaliação para as classificações 5, 6 ou 7. 
II. De 0-10, quanto você se preocupa com o seu desenvolvimento de:

$$
\begin{gathered}
\text { hard skills }-40,2 \% \text { classificaram como } 10 \\
54,0 \% \text { classificaram como } 7 \text { a } 9 \\
5,8 \% \text { outros }
\end{gathered}
$$

soft skills $-37,9 \%$ classificaram como $\mathbf{1 0}$

$52,9 \%$ classificaram como 7 a 9

$9,2 \%$ outros

Nesta pergunta, a classificação 10 foi marcada por uma enorme parcela das pessoas, o que demonstra que elas não poderiam se preocupar mais do que já se preocupam com essa questão do desenvolvimento pessoal de skills. Ainda assim, como na questão I, observa-se que a preocupação com hard skills é maior tanto na classificação 10 quanto na categoria dona do intervalo de 7 a 9. Analisando a categoria "outros", ou seja, pessoas que classificaram suas preocupações como 6 ou menos, conclui-se que há mais pessoas que não se preocupam tanto em desenvolver soft skills $(9,2 \%)$ do que pessoas que não se preocupam tanto em desenvolver hard skills $(5,8 \%)$.

III. De 0-10, quanto você acredita que a sua universidade dispõe de atividades extracurriculares (PET, SPE, Empresa Júnior, IC, curso de idiomas, ensino de softwares) que visem o desenvolvimento de soft/hard skills?

\section{$78,6 \%$ classificaram como 7 a $\mathbf{1 0}$ \\ $15,5 \%$ classificaram como 5 ou 6 \\ $5,9 \%$ outros}

A escolha pela grande parte dos respondentes de dar as classificações mais altas é, no geral, uma avaliação positiva. Isso enfatiza uma perspectiva importante para o estudo que é um indicador de que a maior deficiência da universidade no processo de promoção das competências provavelmente está na grade curricular. Para que se traga respostas que consigam confirmar tal lógica, os resultados da questão IV são analisados.

IV. De 0-10, quanto você acredita que o fluxograma do seu curso (matérias obrigatórias, optativas e eletivas) te prepara para o desenvolvimento de:

Gráfico 1 - Desenvolvimento de hard skills pelo fluxograma

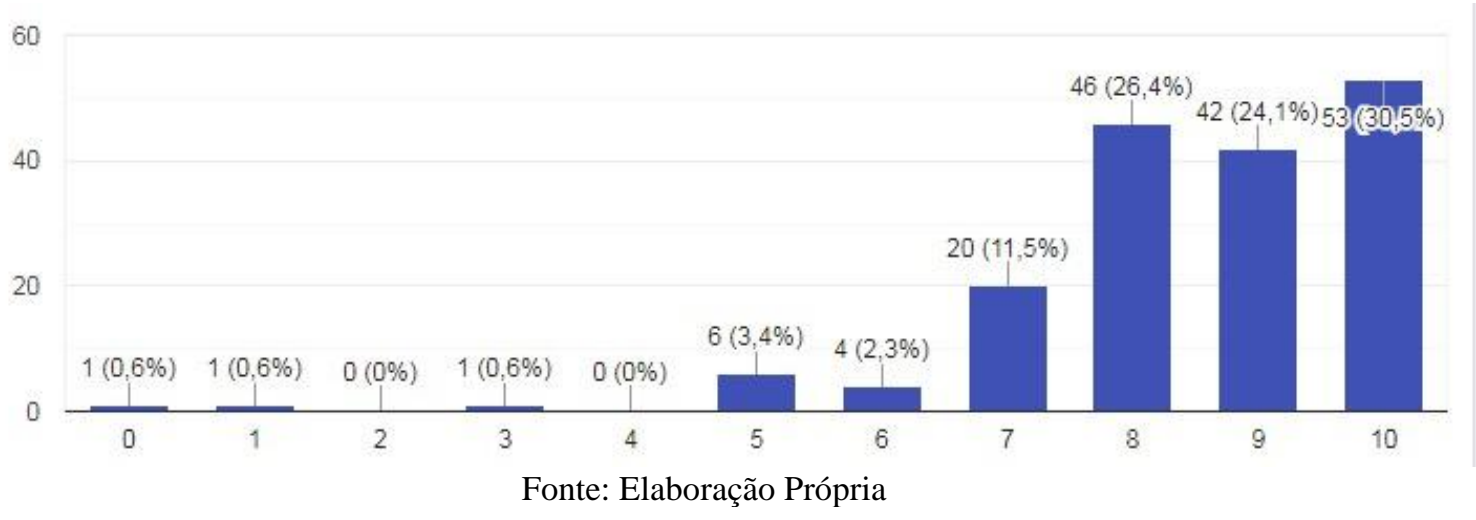


Gráfico 2 - Desenvolvimento de soft skills pelo fluxograma

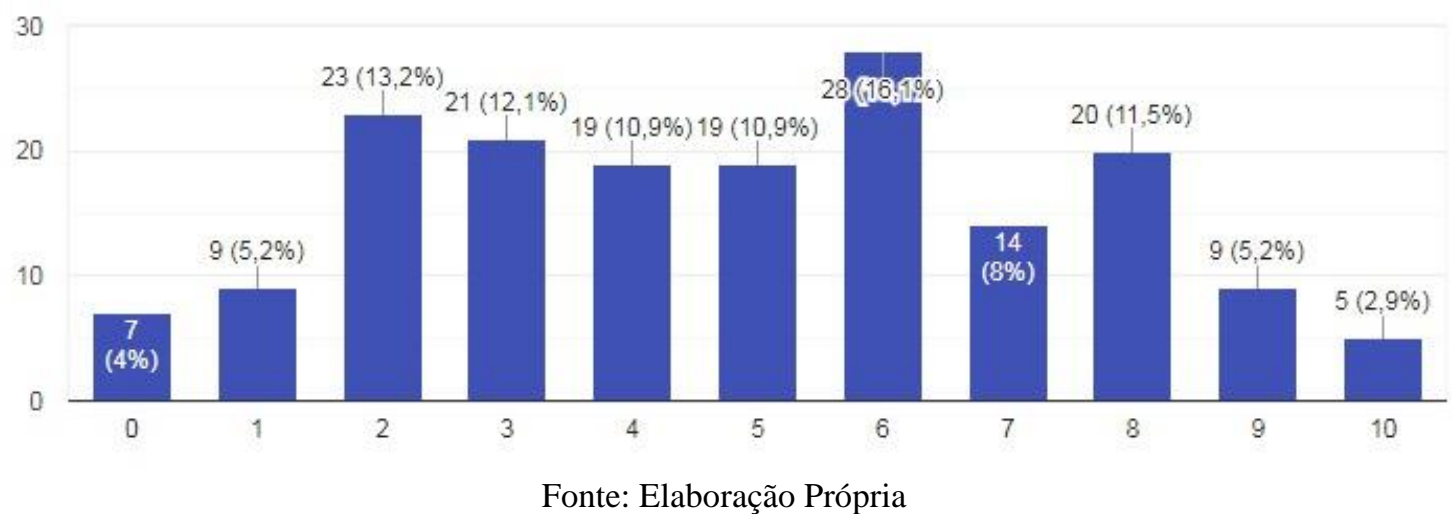

Quanto às soft skills, apesar de as opiniões serem muito diversas, a interpretação do gráfico permite perceber que as avaliações não são majoritariamente altas, isto é, se concentram mais na faixa de 7 a 10, como em todas as avaliações anteriores. Inclusive, mais de $50 \%$ dos respondentes classificou como 0 a 5, o que evidencia uma falta de estrutura da grade curricular do curso com relação ao desenvolvimento de soft skills nos alunos.

Conclui-se que mais de $70 \%$ das pessoas consideram que o fluxograma do curso que fazem ou fizeram tem deficiências no que diz respeito ao desenvolvimento de hard skills, algumas considerando tal deficiência maior, outras menor. Uma solução possível para isso partiria das universidades estabelecerem disciplinas focadas na prática de uso de softwares que são demandados pelo mercado, como Excel, Power BI, Macros, entre outras.

V. Quão preparado você se sente para o mercado de trabalho em relação a domínio de idiomas?

Gráfico 3 - Preparação com relação a idiomas

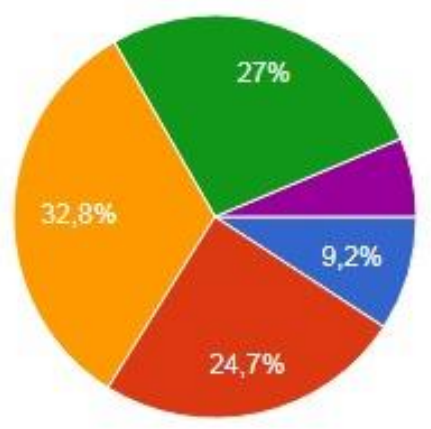

Extremamente preparado

Muito bem preparado

Bem preparado

Pouco Preparado

Nada preparado

Fonte: Elaboração Própria

Apenas para 34\% o domínio de idiomas não é um obstáculo no processo de conseguir um emprego. Logo, esse parâmetro deve ser uma preocupação para uma enorme parte dos respondentes, até mesmo no caso daqueles que se consideram "bem preparados", uma vez que poderá limitar ao longo da carreira opções de emprego que exigem fluência ou que exijam habilidade com 2 ou mais idiomas estrangeiros. Considerado isso, a oferta de aulas de idiomas 
(C) COBENCE 2020

"Os desafios para formar hoje o engenheiro do amanhã"

dentro das universidades mostra-se muito essencial para ajudar a reduzir limitações dessa natureza.

VI. Quão preparado você se sente para o mercado de trabalho?

Gráfico 4 - Preparação para o mercado de trabalho

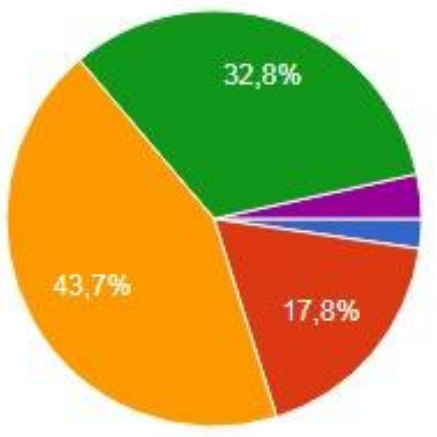

Extremamente preparado

Muito bem preparado

Bem preparado

Pouco Preparado

Nada preparado

Fonte: Elaboração Própria

O setor de petróleo passa com rapidez por diferentes mudanças, as empresas passaram a buscar profissionais melhor preparados e capazes de acompanhar, se adaptar e, inclusive, promover tais transformações. Nesse sentido, nota-se que 63,8\% dos respondentes afirmaram estar devidamente preparados para ingressar no mercado de trabalho, enquanto que $36,2 \%$ acreditam que existe a necessidade de buscar novos caminhos para o desenvolvimento enquanto profissional. Nesse sentido, é interessante a interpretação de que talvez essa falta de preparo sentida por uma parcela dos respondentes poderia estar sendo suprida ou ter sido suprida se as universidades atuassem em seu potencial máximo na promoção de oportunidades acadêmicas como as já mencionadas ao longo do presente trabalho. Diz-se "talvez" pois tal despreparado relatado pode ter origem da falta de interesse e proatividade do próprio universitário.

VII. Selecione dentre as competências listadas as que considera mais importantes.

As competências listadas no Quadro 2 têm se mostrado de suma importância no mercado de trabalho das Engenharias. Por serem de muitas espécies, elas são frequentemente ramificadas em três grandes grupos - competências profissionais, emocionais e tecnológicas - e, ainda, sejam adquiridas ou natas, banais ou raras, entre outras exemplos, qualquer uma pode ser muito importante. Para saber sobre essa questão de forma mais precisa, os respondentes puderam destacar apenas as 5 que consideram mais relevantes atualmente. Não foram estabelecidos critérios ou situações, as pessoas relataram seja pela percepção do que as empresas têm requisitado, por relatos de terceiros ou por experiências próprias. A porcentagem de vezes que cada opção foi escolhida também está representada no Quadro 2. 
Quadro 2 - Competências

\begin{tabular}{|c|c|}
\hline Competência & $\%$ \\
\hline Idiomas & 75,9 \\
\hline Trabalho em Equipe & 74,7 \\
\hline Comunicação & 70,1 \\
\hline Resolução de Problemas & 64,9 \\
\hline Equilíbrio Emocional & 56,9 \\
\hline Proatividade & 55,8 \\
\hline
\end{tabular}

\begin{tabular}{|c|c|}
\hline Competência & $\%$ \\
\hline Microsoft Office & 54,0 \\
\hline Liderança & 49,4 \\
\hline Organização & 48,9 \\
\hline Capacidade de Decisão & 48,9 \\
\hline Inovação & 46,6 \\
\hline Foco em Resultado & 44,3 \\
\hline
\end{tabular}

\begin{tabular}{|c|c|}
\hline Competência & $\%$ \\
\hline Autoconfiança & 41,4 \\
\hline Dinamismo & 40,8 \\
\hline Flexibilidade & 40,8 \\
\hline Empatia & 39,1 \\
\hline Pontualidade & 37,4 \\
\hline Antecipação & 35,1 \\
\hline
\end{tabular}

Fonte: Elaboração Própria

Nesse cenário amostral as competências mais escolhidas foram: idiomas, trabalho em equipe, comunicação e resolução de problemas. Isso reforça os comportamentos existentes na indústria, tendo idiomas como um fator primordial de sucesso devido ao grande número de empresas multinacionais e a diversidade de profissionais. Já o trabalho em equipe e a comunicação são fatores que se relacionam devido à alta multidisciplinaridade de profissionais que atuam nos projetos de petróleo, em prol de buscar soluções eficazes em um curto intervalo de tempo para uma complexidade de operações sincronizadas em ambientes inóspitos.

\section{CONSIDERAÇÕES FINAIS}

O presente trabalho ratifica a importância de se discutir sobre os mecanismos e desafios na formação do Engenheiro, enfatizando a tendência pela busca do desenvolvimento de habilidades que vão além do conhecimento técnico. O estudo de caso evidenciou que os discentes em Engenharia de Petróleo, num âmbito nacional, tem consciência sobre as exigências do setor e se dedicam a esse aspecto, problematizando o papel das Universidades em parte desse processo.

Nesse cenário, o estudo de caso apontou a necessidade de incorporar à grade curricular atividades que proporcionem este desenvolvimento e alinhamento, como situações de relação entre teoria e prática, dinâmicas em equipe e utilização de softwares auxiliares aos conteúdos estudados. Já as atividades extracurriculares se mostram como protagonistas, isso pois instigam de forma rápida e eficiente as hard e soft skills, e devem ser incentivadas.

\section{REFERÊNCIAS}

ANP. Agência Nacional de Petróleo, Gás Natural e Biocombustíveis. Disponível em: http://www.anp.gov.br/. Acesso em: 22 jun. 2020.

SHECAIRA, F. et al. Proposta Curricular para os Cursos de Bacharelado em Engenharia de Petróleo. $1^{\text {a }}$ ed. Rio de Janeiro: SPE (Society of Petroleum Engineering) Seção Brasil, 2013.

SILVA, D. M.; GUIMARÃES, L. N. C. C. Análise crítica e recomendações para o curso de graduação em Engenharia de Petróleo da UFF. 2018. 71 f. TCC (Graduação) - Curso de 
Engenharia de Petróleo, Departamento de Engenharia Química e de Petróleo, Universidade Federal Fluminense, Niterói, 2018.

\title{
STUDY CASE: THE DEMAND FOR SOFT SKILLS AND HARD SKILLS IN THE PETROLEUM ENGINEER BY INDUSTRY 4.0'S LABOR MARKET
}

\begin{abstract}
In the panorama of Industry 4.0 the phenomenon of digital transformation comes on the scene, reshaping the industry and the professional profile demanded by the companies. The text ranks for main analysis the oil \& gas engineer, studying the relevance of soft and hard skills in the the current labor market. This way, the following are discussed: the agents responsible for promoting those skills, the opportunities offered by the Universidade Federal Fluminense that allow such promotion, and the results of a study of case about the qualification of petroleum engineering students and professionals.
\end{abstract}

Keywords: Petroleum Engineering. Oil and Gas. Soft skills. Hard skills. Labor market. 